\title{
Identification and Characterization of a Novel Etiological Agent of Mango Malformation Disease in Mexico, Fusarium mexicanum sp. nov.
}

\author{
Gabriel Otero-Colina, Gerardo Rodríguez-Alvarado, Sylvia Fernández-Pavía, Marcel Maymon, Randy C. Ploetz, \\ Takayuki Aoki, Kerry O’Donnell, and Stanley Freeman
}

First author: Colegio de Postgraduados, Campus Montecillo, Montecillo, Edo. Mex., C.P. 56230 México; second and third authors: Laboratorio de Patología Vegetal, IIAF, Universidad Michoacana de San Nicolás de Hidalgo, Km. 9.5 Carr. Morelia-Zinapécuaro, Michoacán 58880, México; fourth and eighth authors: Department of Plant Pathology and Weed Research, Agricultural Research Organization (ARO), The Volcani Center; P.O. Box 6, Bet Dagan, 50250, Israel; fifth author: Department of Plant Pathology, Tropical Research and Education Center, University of Florida, 18905 SW 280th Street, Homestead 33031-3314; sixth author: NIAS Genebank (MAFF), National Institute of Agrobiological Sciences, 2-1-2, Kannondai, Tsukuba, Ibaraki 305-8602 Japan; and seventh author: Bacterial Foodborne Pathogens and Mycology Research Unit, United States Department of Agriculture-Agricultural Research Service-NCAUR, 1815 N. University St., Peoria, IL 61604.

Accepted for publication16 June 2010.

\begin{abstract}
Otero-Colina, G., Rodríguez-Alvarado, G., Fernández-Pavía, S., Maymon, M., Ploetz, R. C., Aoki, T., O'Donnell, K., and Freeman, S. 2010. Identification and characterization of a novel etiological agent of mango malformation disease in Mexico, Fusarium mexicanum sp. nov. Phytopathology 100:1176-1184.

The primary objective of this study was to characterize Fusarium spp. associated with the economically devastating mango malformation disease (MMD) in Mexico. In all, 142 Fusarium strains were isolated from symptomatic mango inflorescences and vegetative tissues in eight geographically diverse Mexican states from 2002 through 2007. Initially, all the Mexican isolates were screened for genetic diversity using appolymerase chain reaction and random amplified polymorphic DNA markers and were grouped into seven distinct genotypes. Based on results of these analyses, evolutionary relationships and species limits of the

phylogenetically distinct Fusarium spp. within the Gibberella fujikuroi species complex are associated with MMD, including one species within the African clade (Fusarium pseudocircinatum), two species within the Asian clade ( $F$. mangiferae and $F$. proliferatum), and at least six species within the American clade (F. sterilihyphosum and five undescribed Fusarium spp.). Molecular phylogenetic analyses indicate that a novel genealogically exclusive lineage within the American clade was the predominant MMD associate in Mexico. This new Fusarium sp. caused MMD and could be distinguished from all other known species morphologically by the production of mostly sterile, coiled hyphae which are typically associated with sporodochial conidiophores together with unbranched or sparsely branched aerial conidiophores. Koch's postulates were completed for isolates of the new species on nucellar seedlings of mango cv. Ataulfo. This pathogen is formally described herein as $F$. mexicanum.
\end{abstract} genetically diverse MMD-associated Fusarium spp. were investigated using multilocus DNA sequence data and phylogenetic species recognition. Maximum parsimony analyses of a five-locus data set comprising $5.8 \mathrm{~kb}$ of aligned DNA sequence data indicated that at least nine
Additional keywords: Fusarium moniliforme, F. subglutinans, genealogical concordance phylogenetic species recognition (GCPSR), Mangifera indica.
Mango (Mangifera indica) malformation disease (MMD) limits production in several subtropical and tropical regions worldwide. Although first reported in India over a century ago $(10,14,34)$, this disease was not detected in Mexico until 1958 (28). MMD symptoms include malformed inflorescences which usually do not produce fruit and vegetative malformation of seedlings and mature trees $(26,32,34,38)$. Until 1999 (32), a single MMD pathogen, reported variously as Fusarium moniliforme (10) and $F$. subglutinans (25), was recognized. With molecular phylogenetic analyses of multilocus DNA sequence data, Britz et al. (2) redescribed the pathogen as $F$. mangiferae; it is the most widely spread MMD pathogen and predominates in the Eastern Hemis-

Corresponding author: S. Freeman; E-mail address: freeman@ volcani.agri.gov.il

* The $\boldsymbol{e}$-Xtra logo stands for "electronic extra" and indicates that the online version contains a supplemental table and Figure 5 appears in color.

doi:10.1094/PHYTO-01-10-0029

This article is in the public domain and not copyrightable. It may be freely reprinted with customary crediting of the source. The American Phytopathological Society, 2010 phere but is only known in Florida in the Western Hemisphere. Britz et al. (2) also described a second species that was mentioned by Steenkamp et al. (32), F. sterilihyphosum; it was found later in Brazil and shown by Lima et al. (13) to also cause the disease. Subsequent work has revealed two additional species within the Gibberella fujikuroi species complex (GFSC) that are associated with MMD. Lima et al. (13) recently completed Koch's postulates with an undescribed Fusarium sp. from Brazil. A fourth species within the GFSC, an undescribed Fusarium sp. isolated from malformed mangos grown in Michoacán, Mexico (28), is the primary focus of this study.

Various molecular markers have been used to characterize MMD-associated Fusarium spp., including single (28) and multilocus DNA sequence data $(13,14,18,21,32)$, amplified fragment length polymorphisms (AFLPs) (12), random amplified polymorphic DNA (RAPD) (39), and polymerase chain reaction (PCR)based mating type idiomorph assays (2). Due in large part to the dearth of morphological characters in these fungi, multigene molecular phylogenetics first identified the MMD pathogens $F$. mangiferae (reported as Fusarium sp. by O'Donnell et al. [21]) and F. sterilihyphosum (reported as Fusarium sp. by O'Donnell et 
al. [21] and as F. subglutinans by Steenkamp et al. [32]) as phylogenetically distinct, prior to the discovery of morphological apomorphies by Britz et al. (2) that were used in the formal description of these two species. More recently, Lima et al. (13) used multigene phylogenies to distinguish a novel MMD pathogen within the American clade of the GFSC from Brazil. It has not been named formally but was denoted " $F$. subglutinans" in a subsequent article (12); this species is listed as Fusarium sp. no. 1 in the present article because it is morphologically and phylogenetically distinct from $F$. subglutinans. Although the occurrence of mating type 1 (MAT-1) and 2 (MAT-2) isolates of F. mangiferae and $F$. sterilihyphosum suggests that these species may reproduce sexually in nature (2), a teleomorph has not been discovered. The new Brazilian lineage Fusarium sp. no. 1 was thought to be clonal (12).

Due to the serious impact that MMD has on the production of this crop in Mexico (28), Brazil (12,13), South Africa (2,32), and elsewhere (14), the present study was initiated to (i) elucidate the evolutionary relationships and diversity of species associated with MMD using DNA sequence data from portions of five genes, focusing on novel isolates collected in Mexico; (ii) formally describe the primary MMD pathogen from Mexico as Fusarium mexicanum using detailed morphological data; and (iii) complete Koch's postulates for F. mexicanum.

\section{MATERIALS AND METHODS}

Fungal cultures and growth conditions. All isolates used in this study (supplemental table) were single spored, cultured in the dark on potato dextrose agar (PDA; Difco Laboratories, Detroit), and maintained at $25^{\circ} \mathrm{C}$. For DNA extraction, liquid cultures containing $25 \mathrm{ml}$ of potato dextrose broth (PDB; Difco Laboratories) in $10-\mathrm{cm}$ petri dishes were inoculated with two mycelial disks derived from colony margins. The cultures were grown without shaking for 7 days in the dark and maintained at $25^{\circ} \mathrm{C}$ before isolating and extracting DNA. Additional representative cultures were received from Paula Kelly, CABI Global Plant Clinic, London; Ludwig Pfenning, Universidade Federal de Lavras, Brazil; and Emma T. Steenkamp, University of Pretoria, South Africa (supplemental table).

Isolation and purification of fungal DNA. For ap-PCR and RAPD analyses, DNA was extracted from freshly harvested (100 to $200 \mathrm{mg}$ ) or lyophilized (10 to $20 \mathrm{mg}$ ) mycelia of all Fusarium cultures (supplemental table), as described previously (5). The DNA was subsequently dissolved in $0.5 \mathrm{ml}$ of $1 \times$ Tris-EDTA buffer (10 mM Tris-HCl, $1 \mathrm{mM}$ EDTA, $\mathrm{pH}$ 8.0) to an approximate concentration of 200 to $500 \mu \mathrm{g} / \mathrm{ml}$ and diluted to a final concentration of $50 \mathrm{ng} / \mu \mathrm{l}$ for PCR reactions.

PCR amplification of fungal DNA. RAPD- and ap-PCR for genotyping of isolates as a preliminary screen and specific identification of $F$. mangiferae via PCR, was performed on DNAs from 113 isolates of $F$. mexicanum, 29 isolates of Fusarium spp., and 1 representative isolate each of $F$. mangiferae (MRC 7560) and $F$. sterilihyphosum (MRC 7602) (2) (supplemental table). Furthermore, analysis of MAT-1 and 2 MAT-2 was determined for various isolates of $F$. mexicanum (supplemental table) based on Steenkamp et al. (33). RAPD-PCR was conducted with 10-base primer OPF-08 (GGGATATCGG) (Kit F; Operon Technologies, Alameda, CA), ap-PCR with four repeat motif primersCAGCAGCAGCAGCAG, AGGAGGAGGAGGAGG, GACACGACACGACAC, and GACAGACAGACAGACA, designated as $(\mathrm{CAG})_{5},(\mathrm{AGG})_{5},(\mathrm{GACAC})_{3}$, and (GACA $)_{4}$, respectively (5)while specific identification of $F$. mangiferae included the primer pair 1-3F/R (forward: 5' -TGCAGATAATGAGGGTCTGC-3'; reverse: 5'-GGAACATTGGGCAAAACTAC-3') (39). PCR amplification of MAT-1 and MAT-2 were analyzed using the respective primer pairs GFmatla and GFmatlb (forward 5'-GTTCATCAAAGGGCAAGCG-3'; reverse 5'-TAAGCGCCCTCTTA-
ACGCCTTC-3') and GFmat2c and GFmat2d (forward 5'AGCGTCATTATTCGATCAAG-3'; reverse 5'-CTACGTTGAGAGCTGTACA-3') (33).

All PCR reactions were performed in a total volume of $20 \mu$, containing approximately $50 \mathrm{ng}$ of genomic DNA; $50 \mathrm{mM} \mathrm{KCl}$; $10 \mathrm{mM}$ Tris-HCl; $0.2 \mathrm{mM}$ each dATP, dCTP, dGTP, and dTTP;

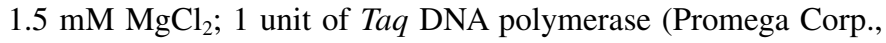
Madison, WI); and $0.5 \mu \mathrm{M}$ each primer. The reactions were incubated in a PTC-100 thermocycler (MJ Research, Inc., MA) starting with 1 min of denaturation at $95^{\circ} \mathrm{C}$ and ending with a final elongation step for $5 \mathrm{~min}$ at $72^{\circ} \mathrm{C}$. For RAPD-PCR, the initial denaturation step was followed by 45 cycles consisting of 1 $\min$ at $94^{\circ} \mathrm{C}, 1 \mathrm{~min}$ at $34^{\circ} \mathrm{C}$, and $2 \mathrm{~min}$ at $72^{\circ} \mathrm{C}$ and, for ap-PCR, by 30 cycles consisting of $30 \mathrm{~s}$ at $95^{\circ} \mathrm{C}, 30 \mathrm{~s}$ at either $60^{\circ} \mathrm{C}$ (for $(\mathrm{CAG})_{5}$ and $\left.(\mathrm{AGG})_{5}\right)$ or $48^{\circ} \mathrm{C}$ (for $(\mathrm{GACA})_{4}$ and $\left.(\mathrm{GACAC})_{3}\right)$, and $1.5 \mathrm{~min}$ at $72^{\circ} \mathrm{C}$. For $F$. mangiferae-specific identification, the initial denaturation step was followed by 40 cycles consisting of $15 \mathrm{~s}$ denaturing at $94^{\circ} \mathrm{C}, 30 \mathrm{~s}$ annealing at $68^{\circ} \mathrm{C}$, and $60 \mathrm{~s}$ at $72^{\circ} \mathrm{C}$. Using an annealing temperature of $68^{\circ} \mathrm{C}$, a specific fragment of $608 \mathrm{bp}$ was only amplified from an isolate of $F$. mangiferae (39). For detection of MAT-1 and MAT-2 idiomorphs, the denaturation step was followed by 35 cycles consisting of $30 \mathrm{~s}$ of denaturing at $92^{\circ} \mathrm{C}, 30 \mathrm{~s}$ of annealing at $67^{\circ} \mathrm{C}$, and $30 \mathrm{~s}$ at $72^{\circ} \mathrm{C}$. Specific fragments of 200 or $800 \mathrm{bp}$ were amplified for the MAT-1 and MAT-2 fragments, respectively (33), using an annealing temperature of $67^{\circ} \mathrm{C}$. Amplification products were separated in agarose gels $(1.5 \%$ [wt/vol]; 15 by $10 \mathrm{~cm}$, width by length) in Tris-acetate-EDTA buffer electrophoresed at $80 \mathrm{~V}$ for $2 \mathrm{~h}$. All PCR experiments were conducted at least five times on DNA from independently cultured fungi with identical results being recorded.

Phylogenetic diversity of MMD-associated Fusarium spp. To obtain mycelium for DNA extraction for multilocus analyses, isolates were grown in $100 \mathrm{ml}$ of yeast-malt broth $(20 \mathrm{~g}$ of dextrose, $5 \mathrm{~g}$ of peptone, $3 \mathrm{~g}$ of yeast extract, and $3 \mathrm{~g}$ of malt extract per liter) (Difco Laboratories) in 300-ml Erlenmeyer flasks on a rotary shaker at $100 \mathrm{rpm}$ for 2 to 3 days. Mycelium was harvested over a Büchner funnel onto Whatman no. 1 70-mm filter paper circles (Schleicher and Schuell, Keene, NH) and then freeze dried. A hexadecyltrimethyl-ammonium bromide (SigmaAldrich, St. Louis) protocol was used to extract total genomic DNA from freeze-dried mycelium (18). Portions of the following five nuclear genes were PCR amplified and sequenced for selected isolates (Table 1), as previously described $(18,19,21)$ : $\beta$-tubulin, calmodulin, translation elongation factor $(E F-1 \alpha)$, histone $\mathrm{H} 3$, and the nuclear ribosomal intergenic spacer region (IGS rDNA). Platinum Taq DNA polymerase (Invitrogen Life Technologies, Carlsbad, CA) was used for all PCR reactions and DNA sequencing was conducted using Applied Biosystems (ABI, Emeryville, CA) BigDye version 3.1 Terminator reaction mix in an ABI 9700 thermocycler, as previously reported (24). The nuclear IGS rDNA was sequenced with the following four internal sequencing primers: iNL11 5'-AGGCTTCGGCTTAGCGTCTTAG, NLa 5'AGGCTTCGGCTTAGCGTCTTAG, iCNS1 5'-TTTCGCAGTGAGGTCGGCAG, and CNSa 5'-TCTCATRTACCCTCCGAGACC (19). ABI DNA sequence chromatograms were edited and aligned with Sequencher version 4.1.2 (Gene Codes; Ann Arbor, MI). TextPad version 5.1.0 for windows (http://www.textpad.com/) was used to manually improve the alignments prior to phylogenetic analysis.

Phylogenetic analysis. Maximum parsimony (MP) analyses were implemented in PAUP* $4.0 \mathrm{~b} 10$ (35) and maximum likelihood (ML) in GARLI version 0.951 (40) as previously described (22). MrModeltest version 2.2 (27) identified the general-timereversible model with a proportion of invariant sites and gamma distributed rate heterogeneity $(\mathrm{GTR}+\mathrm{I}+\Gamma)$ as the best fit model of nucleotide substitution for the ML analyses. Model selection was by using the Akaike Information Criterion. 
Nucleotide sequence accession numbers. The DNA sequences determined in this study have been deposited in GenBank under accession numbers GU737267 to GU737538.

Morphological examination and description of $F$. mexicanum from Mexican mango. Strains were grown at $20^{\circ} \mathrm{C}$ in complete darkness in 9-cm plastic petri dishes on PDA (Difco Laboratories) for examination of colony color, odor, and growth rates or on synthetic low-nutrient agar (SNA) (17) for all microscopic studies and measurements (1). Measurement of nonseptate aerial conidia and three-septate sporodochial conidia was based on 50 conidia selected randomly from individual strains incubated on the SNA plates grown at $20^{\circ} \mathrm{C}$ in the dark for 14 days. Minimal and maximal sizes, arithmetic means, and standard deviations (SDs) were obtained for each character from the strains studied. All colors are given according to the Methuen Handbook of Colour (9).

Strains of F. mexicanum for which morphological characteristics were described are stored cryogenically at $-175^{\circ} \mathrm{C}$ in the Agriculture Research Service Culture Collection (NRRL), National Center for Agricultural Utilization Research, Peoria, IL. A representative specimen of the new species, a dried culture of NRRL 53147, has been deposited as BPI 879150 at the U.S. National Fungus Collections (BPI), Systematic Mycology and Microbiology Laboratory, United States Department of Agriculture-Agricultural Research Service, Beltsville, MD.

Pathogenicity on mango of $F$. mexicanum isolates from Mexico. Nucellar embryos (maternal clones) of mango cv. Ataulfo were separated from germinating seed and grown for 6 months in individual 30-cm-diameter pots. NRRL 53135 (=GR1), NRRL 53139 (=GR10), NRRL 53140 (=GR11), and NRRL 53143 $(=$ GR15) were grown on carnation leaf agar (CLA) plates (11) for 12 days. Conidia were then harvested, diluted to $5 \times 10^{7}$ conidia/ml, and used to inoculate dormant apical buds as previously described by Freeman et al. (4).

\section{RESULTS}

Genetic analyses of $F$. mexicanum and other Fusarium spp. associated with MMD. DNA from representative isolates of $F$. mangiferae (MRC 7560) and F. sterilihyphosum (MRC 7602), and 142 Fusarium MMD-associated isolates from Mexico were amplified with species-specific $F$. mangiferae primers. An $F$. mangiferae-specific amplicon of 608 bp was only amplified from the representative $F$. mangiferae isolate (data not shown). Genotyping of all 142 isolates was conducted using ap-PCR with four repeat-motif primers and one RAPD primer as a preliminary screen. Among the 142 isolates, a genetically distinct MMD pathogen, herein formally described as $F$. mexicanum, contained three unique genotypes. Isolates of each genotype contained identical banding patterns with primers (GACA $)_{4}$ and OPF8 respectively (data not shown), and primers $(\mathrm{CAG})_{5},(\mathrm{AGG})_{5}$, and $(\mathrm{GACAC})_{3}$ (data not shown). In all, 92 isolates of $F$. mexicanum were designated as genotype 1, 17 as genotype 3, and 4 as genotype 6; they were represented by isolates NRRL 53580 (=GOC521), NRRL 53571 (=GOC513), and NRRL 53575 (=GOC692), respectively (data not shown). Four additional genotypes were detected: $2,4,5$, and 7 , which were represented by isolates NRRL 53570 (=GOC504), NRRL 53574 (=GOC539), NRRL 53573 (=GOC537), and NRRL 53576 (=GOC725), respectively, containing $5,15,5$, and 3 isolates each (supplemental table). They were subsequently identified via molecular phylogenetics (see below) as F. pseudocircinatum, Fusarium sp. no. 2, F. pseudocircinatum, and Fusarium sp. no. 3, respectively. Both mating types, MAT-1 and MAT-2, were represented among the isolates of $F$. mexicanum (supplemental table).

Phylogenetic diversity of mango-associated Fusarium spp. A 39-isolate matrix was assembled to investigate evolutionary relationships and species limits of $26 \mathrm{MMD}$-associated isolates within the GFSC. These isolates were geographically and phylogenetically diverse and included 10 from Mexico that represented five phylogenetically distinct species, 11 of Fusarium sp. no. 1 from Brazil (13), 3 of $F$. sterilihyphosum from South Africa, 1 of $F$. mangiferae from India, and 1 of $F$. proliferatum from Malaysia, based on RAPD-PCR and ap-PCR data (supplemental table). Summary sequence and tree statistics for the individual and combined data sets analyzed by unweighted MP are provided in Table 1. MP analyses of the individual partitions revealed that the IGS rDNA was the most informative locus, based on parsimony informative characters (21.6\% of all IGS bp) (Table 1$)$.

To assess whether DNA sequence data from the five gene partitions could be analyzed as a combined data set, we used an MP bootstrap (MP-BS) value of $\geq 70 \%$ as a threshold to identify potential topological incongruence. These analyses failed to detect any strongly supported incongruent nodes, indicating that the data sets could be combined for the MP analysis in PAUP* (35). MP searches for the shortest MP trees employed 1,000 random-sequence-addition replicates and tree-bisection and reconnection (TBR) branch swapping. MP clade support, using nonparametric bootstrapping, employed 1,000 pseudoreplicates of the data, 10 random-addition sequences per replicate, and TBR branch swapping.

Sequences of $F$. oxysporum NRRL 22902 and NRRL 20433 were used to root the trees based on prior analyses of the GFSC $(18,21)$. MP analysis of the combined data set identified three most-parsimonious trees 2,162 steps in length that differed only in minor rearrangements within $F$. sterilihyphosum (Fig. 1). Of the 26 mango-associated isolates analyzed in the 39-isolate data set, 22 were nested within the American clade, 2 within the African clade, and 2 within the Asian clade (Fig. 1).

The American clade contained at least five phylogenetically distinct species associated with MMD, including F. sterilihyphosum and four undescribed species. One of the undescribed species, which appears to represent the basal-most divergence within the American clade, is formally described herein as $F$.

TABLE 1 . Tree statistics and summary sequence for the 39-Fusarium isolate matrix

\begin{tabular}{|c|c|c|c|c|c|c|c|c|c|}
\hline Locus & No. of characters & SYN $^{\mathrm{a}}$ & $\mathrm{AUT}^{\mathrm{b}}$ & No. of MPTs ${ }^{c}$ & MPT length & $\mathrm{Cl}^{\mathrm{d}}$ & $\mathrm{RI}^{\mathrm{e}}$ & PIC/locus (\%) & $\operatorname{BS}(\%)^{\mathrm{f}}$ \\
\hline$\beta$-Tubulin & 1,258 & 105 & 53 & $>100$ & 196 & 0.9 & 0.95 & 8.3 & 98 \\
\hline Calmodulin & 588 & 56 & 35 & 3 & 100 & 0.95 & 0.97 & 9.5 & $<70$ \\
\hline$E F-1 \alpha$ & 675 & 80 & 63 & 31 & 195 & 0.85 & 0.93 & 11.9 & 96 \\
\hline Histone H3 & 466 & 62 & 39 & 56 & 148 & 0.76 & 0.84 & 13.1 & $<70$ \\
\hline IGS rDNA ${ }^{g}$ & 2,735 & 595 & 225 & $>100$ & 1,475 & 0.69 & 0.82 & 21.6 & 86 \\
\hline Combined & 5,822 & 898 & 415 & 3 & 2,162 & 0.73 & 0.84 & 15.4 & 100 \\
\hline
\end{tabular}

${ }^{a} \mathrm{SYN}=$ synapomorphies or parsimony-informative characters (PICs).

${ }^{\mathrm{b}}$ AUT $=$ Autapomorphies or parsimony-uninformative characters.

c MPTs $=$ most-parsimonious trees.

${ }^{\mathrm{d}} \mathrm{CI}=$ consistency index.

${ }^{\mathrm{e}} \mathrm{RI}=$ retention index.

${ }^{\mathrm{f}} \mathrm{BS}=$ bootstrap support for $F$. mexicanum monophyly.

$\mathrm{g}$ IGS rDNA = nuclear ribosomal intergenic spacer region 
mexicanum (Fig. 1). The six isolates of $F$. mexicanum that were included in this analysis were recovered from mangos with malformed floral and vegetative parts in Michoacán and Guerrero, Mexico. MP bootstrap analyses of the individual and combined partitions support the genealogical exclusivity of $F$. mexicanum in that it was resolved as reciprocally monophyletic in the majority of the individual gene-genealogies (3/5 partitions) (Table 1$)$, and none of the individual partitions contradicted its monophyly. The 16 remaining mango isolates were nested within two sister lineages (92\% MP-BS, 93\% ML-BS) (Fig. 1) within the American clade. One of the lineages (100\% MP-BS/ML-BS) was phylogenetically diverse and included 11 isolates of Fusarium sp. no. 1 from Brazil (13). The second lineage (84\% MP-BS, 91\% ML-BS) contained the three isolates of F. sterilihyphosum from South Africa, NRRL 53576 Fusarium sp. no. 3 from malformed mango floral parts from Veracruz, Mexico, and NRRL 53574 (=GOC539) Fusarium sp. no. 2 from malformed mango floral parts from Campeche, Mexico. The latter isolate appears to be conspecific with two isolates from a diseased Cinchona sp. (quinine; NRRL 53293 and NRRL 53294) from the Democratic Republic of Congo.

The mango-associated isolates within the African clade of the GFSC included NRRL 53570 (=GOC504) from Guerrero and NRRL 53573 (=GOC537) from Campeche from malformed vegetative and floral parts, both of which appear to be conspecific with $F$. pseudocircinatum based on the phylogenetic results and detailed morphological analysis. As reported in the description of this species by Nirenberg and O'Donnell (17), both isolates of this species formed diagnostic prostrate (branching) conidiophores bearing short conidial chains from the apices of polyphialides and sporodochial conidia on SNA agar. Mangoassociated isolates within the Asian clade of the GFSC included NRRL $53578 F$. proliferatum from Malaysia and the MMD pathogen NRRL $25226 F$. mangiferae from India $(2,10,18)$.

To further assess evolutionary relationships of the mangoassociated isolates within the American clade, partial $\beta$-tubulin (1,258 bp) and $E F-1 \alpha(674 \mathrm{bp})$ gene sequences totaling 1,933 bp of aligned nucleotide data were assembled for a 37-isolate matrix which included 34 isolates recovered from MMD-symptomatic mangos (Fig. 2). MP and ML analyses of the 37-isolate data set resolved two strongly supported subclades, one corresponding to F. mexicanum (99\% MP-BS, $100 \%$ ML-BS) and the other comprising the remaining ingroup taxa (99\% MP-BS/ML-BS). Nineteen of the $F$. mexicanum isolates were from Michoacán, whereas the remaining three isolates were from Colima, Guerrero, and Morelos. Although evolutionary relationships of the five MMD-associated species (F. sterilihyphosum, Fusarium sp. no. 1, Fusarium sp. no. 2, Fusarium sp. no. 3, and Fusarium sp. no. 4) within the second subclade were not resolved by the two-locus data set (Fig. 2), the analysis suggests that NRRL 53148 (=GR10; Fusarium sp. no. 4) recovered from malformed mango floral parts in Colima may represent a fourth undescribed, phylogenetically

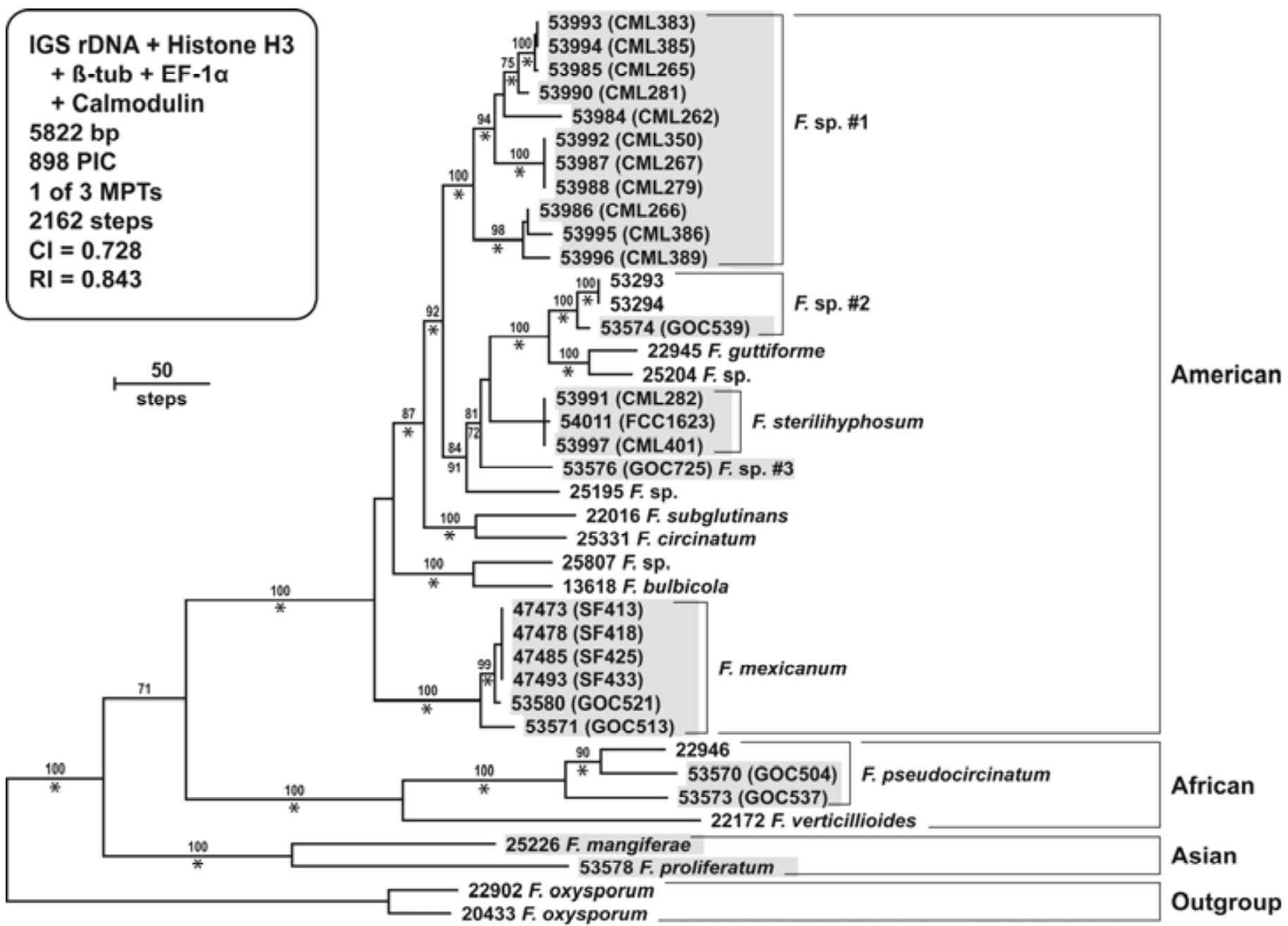

Fig. 1. One of three most-parsimonious trees (MPTs) inferred from the combined five-locus, 39-taxon data set rooted with sequences of Fusarium oxysporum. Bootstrap intervals $\geq 70 \%$ from 1,000 maximum parsimony pseudoreplicates of the data are indicated above nodes; maximum likelihood bootstrap support $\leq 5 \%$ of the maximum parsimony value is indicated by an asterisk below nodes. The 26 isolates representing eight species recovered from mango fruit exhibiting mango malformation disease (MMD) symptoms are highlighted in gray. Note that MMD-associated Fusarium spp. are nested within all three biogeographically structured clades of the Gibberella fujikuroi species complex. IGS rDNA = nuclear ribosomal intergenic spacer region and PIC $=$ parsimony-informative character. 
distinct species. Because Fusarium sp. no. 3 and Fusarium sp. no. 4 were both represented by a limited number of isolates, additional sampling is necessary to fully assess the species limits of these putative phylogenetically distinct species. Consistent with published reports $(2,13,32)$, our analyses revealed little genetic variation within isolates of $F$. sterilihyphosum from South Africa and Brazil (Figs. 2 and 3).

Fusarium mexicanum T. Aoki, S. Freeman, Otero-Colina, Rodríguez-Alvarado, Fernández-Pavía, Ploetz et O'Donnell, sp. nov. A novel causal fungus of mango malformation disease in Mexico is described and illustrated here as a new species of Fusarium (Figs. 4 and 5).

Coloniae in PDA dicto radium per diem $1.8-3.1 \mathrm{~mm}$ ad $20^{\circ} \mathrm{C}$ obscuritate crescentes. Mycelium aerium laxe vel dense floccosum, nonnumquam funiculosum, album vel rubro-album vel purpureo-album vel griseo-purpureum. Chlamydosporae et sclerotia absentes. Sporodochia in lucibus omnibus in vel super agaro formata. Hyphae circinaria plerumque copiose formatae, nonnumquam absentes, multiseptata, 2-2.5 $\mu \mathrm{m}$ latae, ramificantes vel non ramificantes, ut plurimum steriles, raro in apice vel in ramis lateralibus monophialides efformantes, frequenter cum condiophoris sporodochialibus associata. Conidiophora aeria plerumque erecta, aliquando prostrata, simplicia vel parce ramosa in phialides terminania, nonnumquam sympodialiter proliferantia. Cellulae conidiogenae in conidiophoris aereis monophialidicae vel polyphialidicae. Conidiae in mycelio aerio in obscuritate in falsis capitibus vel massis amorphis. Conidia aeria 0(-2)-septata, breviter clavata vel ellipsoidea, plerumque recta, nonnumquam curvata; conidia reniformia ad quasi C-formia etiam praesenia, ubi recta et 0 -septata in obscuritate $4-18.5 \times 1-3.5 \mu \mathrm{m}$, ubi Cformia in obscuritate $6.5-27.5 \times 1.5-5.5 \mu \mathrm{m}$. Conidia fusiformia, recta sive curvata, 1-3-septata sine cellulis pediformibus, in conidiophoris aeris nonnumquam efformata; 3-septata: $25-37 \times$ 3-5 $\mu \mathrm{m}$. Conidia sporodochialia (1-)3(-5)-septata, falcata et curvata, dorsiventralia, in dimidio superiore saepe leviter dilatata, utrinque angustata, cum cellulis apicalibus acuminatis, quasi angustum rostrum, cum cellulis basalibus clare pediformibus, praesertim in sporodochiis efformata; 3-septata: $21.5-62 \times 1.5-5 \mu \mathrm{m}$.

On PDA, colonies grow $1.8-3.1 \mathrm{~mm}$ per day at $20^{\circ} \mathrm{C}$ in the dark. Aerial mycelia are loosely to densely floccose, sometimes funiculose, white (1A1), pinkish white (7-8A2), violet white (1617A2), pale violet (16-17A3), to grayish violet (16-17B3-4). Pigmentation in the reverse is pale yellow (4A3), pale orange (5A3), lilac (15-16BC3-4), lilac gray (15-16BC2), sometimes partly dark purple (14F3-4) to dark violet (15-16F3-4) at the center. Chlamydospores and sclerotial bodies are absent. Odor is absent. Sporulation on SNA starts first in the aerial mycelium and later in sporodochia. Sporodochia are observed under all light conditions, on or in the agar. Coiled hyphae generally are formed abundantly but are absent in some strains, multiseptate, 2-2.5 $\mu \mathrm{m}$ wide, branched or unbranched, and mostly sterile, rarely forming monophialides at the tips or on side branches, often associated with sporodochial conidiophores. Aerial conidiophores are mostly erect, some prostrate, unbranched and simple, or branched sparsely and sympodially or verticillately, terminating in phialides. Sympodially proliferating conidiophores are sometimes present. Co-
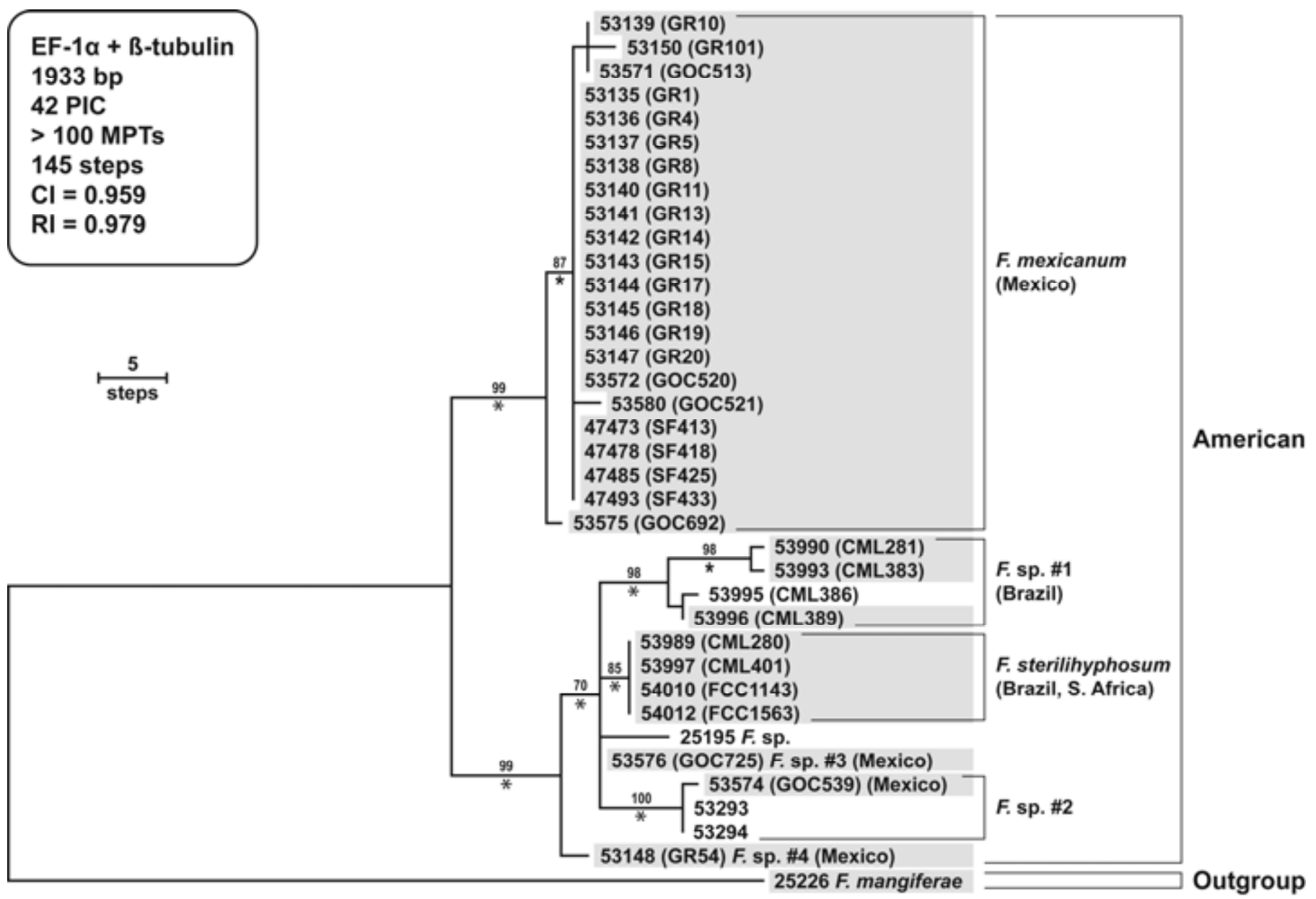

Fig. 2. One of $>100$ most-parsimonious trees (MPTs) inferred from the partial $E F-1 \alpha$ and $\beta$-tubulin gene sequence data for the 37-taxon data set of fusaria. A sequence of the Asian clade mango malformation disease (MMD) pathogen, Fusarium mangiferae, was used to root the ingroup, which consisted of 36 American clade taxa. The 34 isolates associated with MMD are highlighted in gray. Maximum parsimony (MP) bootstrap support $\geq 70 \%$ from 1,000 pseudoreplicates of the data is indicated above nodes. maximum likelihood bootstrap support $\leq 5 \%$ of the MP value is indicated by an asterisk below nodes. PIC $=$ parsimony-informative character, $\mathrm{CI}=$ consistency index, and $\mathrm{RI}=$ retention index. 
nidiogenous cells on the aerial conidiophores are monophialidic or polyphialidic; conidia borne in the aerial mycelium in the dark are arranged in false heads as amorphous masses. Aerial conidia are 0(-2)-septate, short clavate to ellipsoidal, mostly straight, sometimes curved, with reniform to $\mathrm{C}$-shaped conidia also present; straight 0 -septate in darkness: $4-18.5 \times 1-3.5 \mu \mathrm{m}$ in total range, $6.9-9.8 \times 2.3-2.7 \mu \mathrm{m}$ on average (ex type: $4-13 \times 1.5-3$ $\mu \mathrm{m}, 7.7 \pm 1.8 \times 2.42 \pm 0.30 \mu \mathrm{m}$ on average and SD); C-shaped in darkness: $6.5-27.5 \times 1.5-5.5 \mu \mathrm{m}$ in total range, $9.8-13.0 \times 2.3-2.7$ $\mu \mathrm{m}$ on average (ex type: $8-12 \times 2-3 \mu \mathrm{m}, 9.75 \times 2.5 \mu \mathrm{m}$ on average). Fusiform, straight or curved, 1-3-septate conidia without a foot-cell sometimes are formed on aerial conidiophores; 3-septate: $25-37 \times 3-5 \mu \mathrm{m}$ in total range, $28.7-31.0 \times 3.7-3.8 \mu \mathrm{m}$ on average. Sporodochial conidia (1-)3(-5)-septate, falcate and curved, dorsiventral, often widest above the midregion of their length, tapering toward both ends, with an acuminate apical cell forming a narrow beak and a distinct foot-like basal cell, mostly formed in sporodochia on or in the agar, sometimes also observed on conidiophores arising directly from hyphae on the agar; 3septate in darkness: $21.5-62 \times 1.5-5 \mu \mathrm{m}$ in total range, $30.9-43.4$ $\times 2.7-3.8 \mu \mathrm{m}$ on average (ex type: $25-49.5$ by $2.5-4 \mu \mathrm{m}, 36.9 \pm$ $5.9 \times 3.06 \pm 0.33 \mu \mathrm{m}$ on average and SD).

Etymology: mexicanum (Lat.), referring to the type locality of the species.

Holotype: BPI 879150, a dried culture, isolated from diseased vegetative tissues of mango, $M$. indica L., Michoacán, Nueva Italia county, Mexico, on 5 February 2005, by Gerardo
Rodríguez-Alvarado, deposited in the herbarium of BPI (U.S. National Fungus Collection, Beltsville, MD).

Ex holotype culture: NRRL 53147 = Gerardo RodríguezAlvarado GR20.

Isolates studied: NRRL 47473 (=SF413) from diseased mango, M. indica L., Mexico, on 12 May 2007, by Stanley Freeman and Gabriel Otero-Colina; NRRL 47478 (=SF418) from diseased mango, M. indica L., Michoacán, Mexico, on 13 May 2007, by Stanley Freeman and Gabriel Otero-Colina; NRRL 47485 (=F425) from diseased mango, $M$. indica L., Michoacán, Mexico, on 13 May 2007 by Stanley Freeman and Gabriel Otero-Colina; NRRL 47493 (=SF433) from diseased mango, M. indica L., Michoacán, Mexico, on 13 May 2007, by Stanley Freeman and Gabriel Otero-Colina; NRRL 53135 (=GR1) from diseased mango, $M$. indica L., Michoacán, Mexico, on 20 January 2004 by Gerardo Rodríguez-Alvarado; NRRL 53147 (=GR20) from diseased mango, $M$. indica L., Michoacán, Mexico, on 5 February 2005, by Gerardo Rodríguez-Alvarado; NRRL 53150 (=GR101) from diseased mango, M. indica L., Colima, Mexico, on 9 July 2007, by J. Joaquín Velázquez-Monreal; NRRL 53571 (=GOC513) from diseased mango, M. indica L., Guerrero, Mexico, on 20 December 2008, by Gabriel Otero-Colina; NRRL 53580 (=GOC521) from diseased mango, $M$. indica L., Michoacán, Mexico, on 20 December 2008, by Gabriel Otero-Colina.

Pathogenicity on mango of isolates of $F$. mexicanum sp. nov. from Mexico. Symptoms of vegetative malformation developed on inoculated vegetative buds of mango seedlings cv. Ataulfo

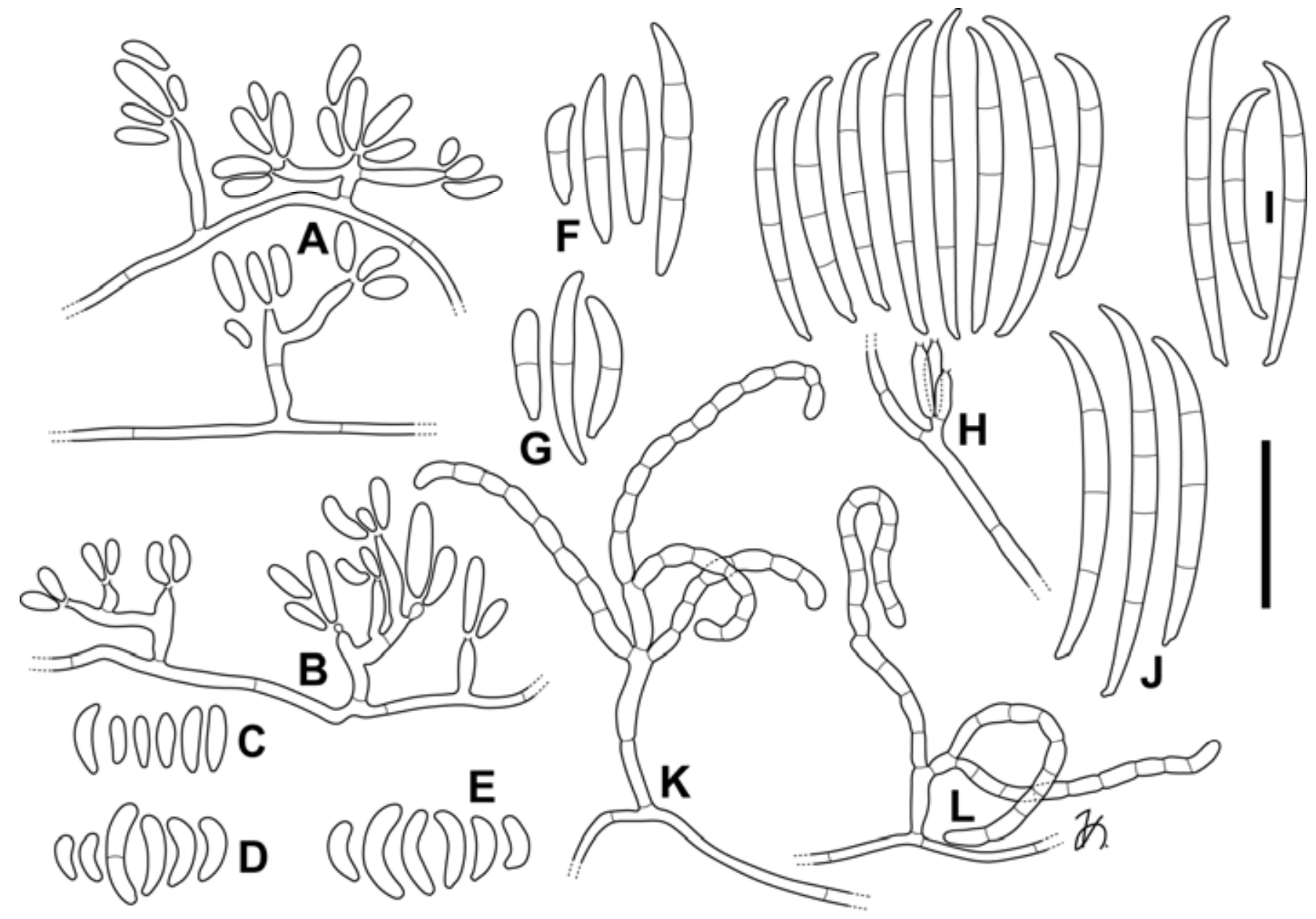

Fig. 3. Microscopic morphology of Fusarium mexicanum. A and B, Simple or branched aerial conidiophores forming zero-septate conidia from mono- or polyphialides. C, Short clavate, zero-septate aerial conidia. D and E, Allantoid or C-shaped, zero-septate aerial conidia. F and G, Fusiform, one- to three-septate aerial conidia without a foot-cell. $\mathbf{H}$, Three-septate sporodochial conidia formed from monophialides. I and $\mathbf{J}$, Multiseptate sporodochial conidia with an acuminate apical beak-like cell and a distinct basal foot-like cell. $\mathbf{K}$ and $\mathbf{L}$, Sterile, coiled septate hyphae. A, E, F, H, and $\mathbf{L}$ from the Agriculture Research Service Culture Collection NRRL 53147 (=GR20); B, D, G, I, and K from NRRL 47473 (=SF413); C and J from NRRL 53150 (=GR101). Scale bar: 25 m. 
after 12 weeks. Each of the four isolates of $F$. mexicanum that were tested (supplemental table) caused typical symptoms that included: swollen buds; short, brittle leaves that curved back toward the supporting stem; and shortened internodes (Fig. 5). The pathogen was recovered from all symptomatic plants.

\section{DISCUSSION}

Results of the present study advance our knowledge of the evolutionary relationships and diversity of species that are associated with MMD. First, they confirm and extend the initial report by Rodríguez-Alvarado et al. (28) that a novel taxon, formally described herein as F. mexicanum, causes MMD in Mexico. Our results demonstrate that this species fulfills the requirements of genealogical concordance phylogenetic species recognition (GCPSR) (36) in that it was reciprocally monophyletic in the majority of the individual gene genealogies (i.e., 3/5) (Table 1) and the genealogical exclusivity of this species was not contradicted by any of the individual gene partitions (3). In related studies, multilocus molecular phylogenetics first identified the MMD pathogen F. mangiferae (reported as Fusarium sp. by O'Donnell et al. [18]) and the MMD-associated species $F$. sterilihyphosum (reported as Fusarium sp. by O'Donnell et al. [21] and F. subglutinans by Steenkamp et al. [32]) as phylogenetically distinct, prior to the discovery of morphological apomorphies used in their formal description (2). The analyses presented here also help formulate more robust hypotheses of sister-group relationships and the evolutionary origins of the MMD-associated Fusarium spp. Although the sister group of $F$. mexicanum was not fully resolved in the present study, its basal position within the American clade suggests that it may have descended from one of the earliest divergences within the GFSC in the New World, and that it is very likely most closely related to species belonging to the American clade. A putative sister-group

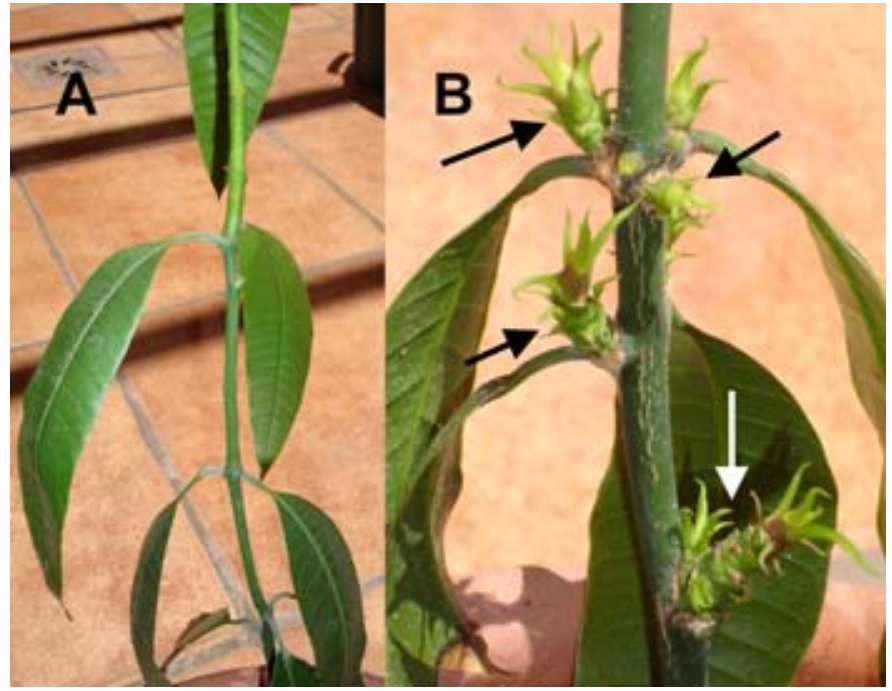

Fig. 5. Nucellar seedlings of mango cv. Ataulfo treated with A, water (control) and $\mathbf{B}$, inoculated with Fusarium mexicanum. Symptoms of vegetative malformation (denoted by arrows) developed approximately 12 weeks following inoculation with each of four tested isolates: Agriculture Research Service Culture Collection NRRL 53135 (=GR1), NRRL 53139 (=GR10), NRRL 53140 (=GR11), and NRRL 53143 (=GR15).

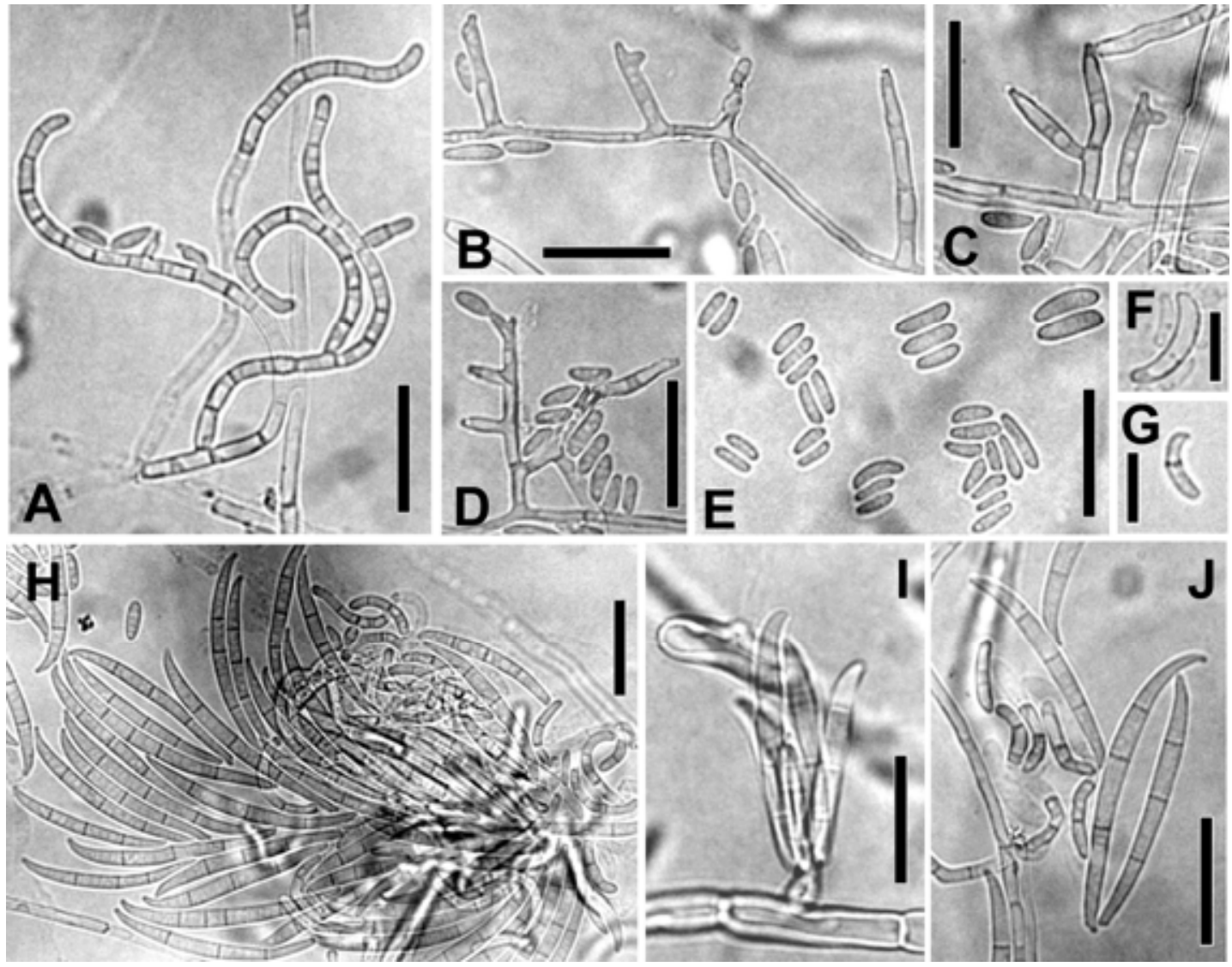

Fig. 4. Diagnostic micromorphology of Fusarium mexicanum. A, Coiled septate hyphae, often sterile but sometimes forming conidia from phialides on the apex or as side branches. B to D, Simple or branched aerial conidiophores forming mono- or polyphialides. E, Short clavate to ellipsoidal, zero-septate aerial conidia. F and G, Zero- or one-septate, C-shaped conidia. H, Multiseptate sporodochial conidia formed on the surface of agar, with adjoining coiled septate hyphae. I, Sporodochial conidia formed from a monophialide. J, Sporodochial conidia often widest above the midregion of their length, with an acuminate apical cell and a distinct basal foot-like cell. All micrographs were from the ex-holotype strain, Agriculture Research Service Culture Collection NRRL 53147 (=GR20). Scale bars: $\mathbf{A}$ to $\mathbf{E}$ and $\mathbf{H}$ to $\mathbf{J}, 20 \mu \mathrm{m} ; \mathbf{F}$ and $\mathbf{G}, 10 \mu \mathrm{m}$. 
relationship was reported for the American clade species $F$. sterilihyphosum and Fusarium sp. no. 1, based on MP analysis of partial $E F-1 \alpha$ and $\beta$-tubulin gene sequences and a phenetic analysis of AFLP data (13). However, our analyses of a five-gene data set and additional taxa indicate that the MMD pathogen from Brazil (Fusarium sp. no. 1) is a sister to a clade that contained $F$. sterilihyphosum and five other species, two of which were recovered from $M$. indica exhibiting MMD symptoms in Mexico (Fig. 1). Interestingly, based on analysis of AFLP data, unweighted pairgroup with arithmetic means clustering within the MMD pathogens Fusarium sp. no. 1, F. sterilihyphosum, and $F$. mangiferae correlated well with vegetative compatibility groups and, generally, with their geographic origin (12). Isolates possessing either a MAT1 or MAT2 idiomorph were identified among the isolates of $F$. mexicanum in the present study (supplemental table) and within $F$. mangiferae and $F$. sterilihyphosum by Britz et al. (2). However, because a PCR assay for the MAT idiomorph was not conducted for Fusarium sp. no. 1 from Brazil (12), it remains to be determined whether both idiomorphs are present in the latter MMD pathogen.

One of the most surprising results to emerge from the present multilocus phylogenetic analyses was the discovery that nine species within the GFSC were resolved among the analyzed MMD-associated isolates (Figs. 2 and 3). Other GCPSR-based studies have consistently revealed similarly high levels of cryptic speciation within the GFSC $(18,21)$ and other species complexes within the genus Fusarium $(20,22,23,29)$. Of the nine MMD associates, four possess Latin binomials, including $F$. mexicanum, which was described formally herein. Remarkably, mangoassociated isolates were represented in all three clades of the GFSC and included one African clade species isolated in Mexico (F. pseudocircinatum), two Asian clade species ( $F$. mangiferae from India and $F$. proliferatum from Malaysia), and $F$. mexicanum, F. sterilihyphosum, and four undescribed species in the American clade. Although additional sampling is needed to fully assess the monophyly of two of the phylogenetic species from Mexico, it is clear that substantial genetic and geographic variation exists among Fusarium spp. that cause and are associated with MMD.

Anthropomorphic activities associated with cultivation of the Asian endemic M. indica and the New World native Cinchona sp. (quinine) may explain the disjunctive distribution of $F$. mangiferae, F. sterilihyphosum, F. pseudocircinatum, and Fusarium sp. no. 2 in the Old and New Worlds $(14,25,31)$. Of the nine MMDassociated species, our data suggest that only $F$. mangiferae and $F$. proliferatum appear to have evolved in the native region of $M$. indica in southern Asia (30). As previously noted, F. mangiferae was shown to be a sister of the NRRL 26477 Fusarium sp. from tropical rain forest soil in Papua New Guinea (23), which is consistent with an evolutionary origin of this MMD pathogen in Asia along with its mango host (30).

Given the broad phylogenetic diversity of Fusarium spp. that are associated with MMD, additional studies are needed to better understand the respective roles that aerial dispersal (7) and various arthropods play in vectoring Fusarium spp. to mango buds, the primary infection site $(6,8)$. It is noteworthy that various generalists, including ants, bees, beetles, butterflies, flies, moths, wasps, and fruit bats (15), and specialists such as the mango bud mite Aceria mangiferae are associated with this crop (6). Research is also needed to determine whether these pathogens possess common attributes, such as cytokinin production $(16,37)$, that enable them to cause malformation symptoms on this crop. Because members of the GFSC's American clade are known to produce fumonisin and moniliformin toxins, studies are also needed to determine the in vivo and in vitro mycotoxin potential of the MMD-associated Fusarium spp.

Based on the detailed study of its micromorphology, $F$. mexicanum can be differentiated from other known species of
Fusarium. F. mexicanum is characterized by its coiled hyphae, which are mostly sterile and typically associated with and often surround sporodochial conidiophores (Figs. 4K and L and 5A and 5). Only three Fusarium spp. within the GFSC have been reported to form coiled sterile hyphae: $F$. circinatum Nirenberg et O'Donnell (17), F. pseudocircinatum O'Donnell et Nirenberg (17), and F. sterilihyphosum Britz et al. $(2,11)$. F. mexicanum can be easily differentiated from these three species based on the morphology of aerial conidiophores and other characters. $F$. circinatum is unique in forming coiled hyphae typically associated with aerial conidiophores whereas, in F. mexicanum, they are normally associated with sporodochial conidiophores (Fig. 4H). The aerial conidiophores of $F$. circinatum frequently branched extensively and irregularly, resulting in a dendroid morphology. By contrast, aerial conidiophores of $F$. mexicanum were either unbranched or sparsely branched (Figs. 4A and B and 5B to D). Like $F$. circinatum, $F$. pseudocircinatum formed extensively branched aerial conidiophores. In addition to producing conidia in false heads, $F$. pseudocircinatum often formed short conidial chains which were absent in $F$. mexicanum. F. sterilihyphosum also produces extensively branched erect aerial conidiophores (11) which distinguish it from F. mexicanum. F. sterilihyphosum rarely produced sporodochia in culture, whereas sporodochia were commonly produced by isolates of $F$. mexicanum (Figs. $4 \mathrm{H}$ to $\mathrm{J}$ and $5 \mathrm{H}$ to $\mathrm{J}$ ). The coiled hyphae produced by $F$. circinatum, $F$. pseudocircinatum, and $F$. sterilihyphosum were all reported as sterile. However, the coiled hyphae of $F$. mexicanum occasionally produced apical or lateral phialides, from which aerial conidia were formed (Fig. 4A), although they remained sterile in most cases (Fig. 3K and L). With one exception (NRRL 53135), the coiled hyphae were formed by strains of $F$. mexicanum we examined. F. mexicanum also formed $\mathrm{C}$-shaped aerial conidia (Figs. 4D and $\mathrm{E}$ and $5 \mathrm{~F}$ and $\mathrm{G}$ ), which may serve as an additional distinguishing morphological feature for this species.

In this study, a genealogically unique species, $F$. mexicanum, is described as the predominant MMD pathogen in Mexico. This novel species, which was characterized by molecular and morphological analyses, is nested within the American clade of the GFSC. At least nine phylogenetically distinct MMD-associated Fusarium spp. have been identified within the three clades of the GFSC, further attesting to the broad genetic and geographic diversity of MMD-associated Fusarium spp. Additional work is warranted to identify features of these genetically and geographically diverse fungi that enable them to cause MMD, such as possessing a unique pathway for cytokinin biosynthesis, reported as a major component in pathogenicity $(10,26)$.

\section{ACKNOWLEDGMENTS}

The mention of firm names or trade products does not imply that they are endorsed or recommended by the United States Department of Agriculture over other firms or similar products not mentioned. We thank S. Sink for generating the multilocus DNA sequence data; D. Fraser for preparing the tree figures; J. Joaquín Velázquez-Monreal, INIFAP, Tecomán, Colima, for kind help during sampling; and P. Kelly (CAB International, UK), J. F. Leslie (Kansas State University), L. Pfenning (University of Federal de Lavras, Brazil), and E. Steenkamp (University of Pretoria, South Africa) for some of the isolates that were used in this study.

\section{LITERATURE CITED}

1. Aoki, T., O'Donnell, K., and Ichikawa, K. 2001. Fusarium fractiflexum sp. nov. and two other species within the Gibberella fujikuroi species complex recently discovered in Japan that form aerial conidia in false heads. Mycoscience 42:461-478.

2. Britz, H., Steenkamp, E. T., Coutinho, T. A., Wingfield, B. D., Marasas, W. F. O., and Wingfield, M. J. 2002. Two new species of Fusarium section Liseola associated with mango malformation. Mycologia 94:722730 . 
3. Dettman, J. R., Jacobson, D. J., and Taylor, J. W. 2003. A multilocus genealogical approach to phylogenetic species recognition in the model eukaryote Neurospora. Evolution 57:2703-2720.

4. Freeman, S., Maimon, M., and Pinkas, Y. 1999. Use of GUS transformants of Fusarium subglutinans for determining etiology of mango malformation disease. Phytopathology 89:456-461.

5. Freeman, S., Pham, M., and Rodriguez, R. J. 1993. Molecular genotyping of Colletotrichum species based on arbitrarily primed PCR, A+T-rich DNA and nuclear DNA analyses. Exp. Mycol. 17:309-322.

6. Gamliel-Atinsky, E., Freeman, S., Sztejnberg, A., Maymon, M., Ochoa, R., Belausov, E., and Palevsky, E. 2009. Interaction of the mite Aceria mangiferae with Fusarium mangiferae, the causal agent of mango malformation disease. Phytopathology 99:152-159.

7. Gamliel-Atinsky, E., Sztejnberg, A., Maymon, M., Shtienberg, D., and Freeman, S. 2009. Inoculum availability and conidial dispersal patterns of Fusarium mangiferae, the causal agent of mango malformation disease. Phytopathology 99:160-166.

8. Gamliel-Atinsky, E., Sztejnberg, A., Maymon, M., Vintal, H., Shtienberg, D., and Freeman, S. 2009. Infection dynamics of Fusarium mangiferae, causal agent of mango malformation disease. Phytopathology 99:775-778.

9. Kornerup, A., and Wanscher, J. H. 1978. Methuen Handbook of Colour, 3rd ed. Eyre Methuen, London.

10. Kumar, J., Singh, U. S., and Beniwal, S. P. S. 1993. Mango malformation: one hundred years of research. Annu. Rev. Phytopathol. 31:217-232.

11. Leslie, J. F., and Summerell, B. A. 2006. The Fusarium Laboratory Manual. Blackwell Publishing, Ames, IA.

12. Lima, C. S., Monteiro, J. H. A., Crespo, N. C., Costa, S. S., Leslie, J. F., and Pfenning, L. P. 2009. VCG and AFLP analyses identify the same groups in the casual agents of mango malformation in Brazil. Eur. J. Plant Pathol. 123:17-26.

13. Lima, C. S., Pfenning, L. H., Costa, S. S., Campos, M. A., and Leslie, J. F. 2008. A new lineage within the Gibberella fujikuroi species complex is the main causal agent of mango malformation disease in Brazil. Plant Pathol. 58:33-42.

14. Marasas, W. F. O., Ploetz, R. C., Wingfield, M. J., Wingfield, B. D., and Steenkamp, E. T. 2006. Mango malformation disease and the associated Fusarium species. Phytopathology 96:667-672.

15. Morton, J. 1987. Mango. Pages 221-239 in: Fruits of Warm Climates. Florida Flair Books, Miami, FL.

16. Nicholson, R. I. D., and van Staden. J. 1988. Cytokinins and mango flower malformation. I. Tentative identification of the complement in healthy and malformed inflorescences. J. Plant Physiol. 132:720-724.

17. Nirenberg, H. I., and O'Donnell, K. 1998. New Fusarium species and combinations within the Gibberella fujikuroi species complex. Mycologia 90:434-458.

18. O’Donnell, K., Cigelnik, E., and Nirenberg, H. 1998. Molecular systematics and phylogeography of the Gibberella fujikuroi species complex. Mycologia 90:465-493.

19. O’Donnell, K., Gueidan, C., Sink, S., Johnston, P. R., Crous, P., Glenn, A., Riley, R., Zitomer, N., Colyer, P., Waalwijk, C., van der Lee, T., Moretti, A., Kang, S., Kim, H.-S., Geiser, D. M., Juba, J., Baayen, R. P., Cromey, M. G., Bithell, S., Sutton, D. A., Skovgaard, K., Ploetz, R., Kistler, H. C., Elliott, M., Davis, M., and Sarver, B. A. J. 2009. A twolocus DNA sequence database for typing plant and human pathogens within the Fusarium oxysporum species complex. Fungal Genet. Biol. 46:936-948.

20. O’Donnell, K., Kistler, H. C., Tacke, B. K., and Casper, H. H. 2000. Gene genealogies reveal global phylogeographic structure and reproductive isolation among lineages of Fusarium graminearum, the fungus causing wheat scab. Proc. Nat. Acad. Sci. USA 97:7905-7910.

21. O’Donnell, K., Nirenberg, H. I., Aoki, T., and Cigelnik, E. 2000. A multigene phylogeny of the Gibberella fujikuroi species complex: detection of additional phylogenetically distinct species. Mycoscience 41:61-78.

22. O’Donnell, K., Sutton, D. A., Fothergill, A., McCarthy, D., Rinaldi, M. G., Brandt, M. E., Zhang, N., and Geiser, D. M. 2008. Molecular phylogenetic diversity, multilocus haplotype nomenclature, and in vitro antifungal resistance within the Fusarium solani species complex. J. Clin. Microbiol. 46:2477-2490.

23. O’Donnell, K., Sutton, D. A., Rinaldi, M. G., Crous, P. W., and Geiser, D. M. 2009. A novel MLST scheme reveals high genetic diversity of human pathogenic members of the Fusarium incarnatum-equiseti and $F$ chlamydosporum species complexes within the U.S. J. Clin. Microbiol. 47:3851-3861.

24. O'Donnell, K., Ward, T. J., Geiser, D. M., Kistler, H. C., and Aoki, T. 2004. Genealogical concordance between the mating type locus and seven other nuclear genes supports formal recognition of nine phylogenetically distinct species within the Fusarium graminearum clade. Fungal Genet. Biol. 41:600-623.

25. Ploetz, R. C. 1994. Distribution and prevalence of Fusarium subglutinans in mango trees affected by malformation. Can. J. Bot. 72:7-9

26. Ploetz, R. C. 2001. Malformation: a unique and important disease of mango, Mangifera indica L. Pages 233-247 in: Fusarium: Paul E. Nelson Memorial Symposium. B. A. Summerell, J. F. Leslie, D. Backhouse, W. L. Bryden, and W. L. Burgess, eds. The American Phytopathological Society, St. Paul, MN.

27. Posada, D., and Crandall, K.A., 1998. MODELTEST: testing the model of DNA substitution. Bioinformatics 14:817-818.

28. Rodríguez-Alvarado, G., Fernández-Pavía, S. P., Ploetz, R. C., and Valenzuela-Vázquez, M. 2008. A Fusarium sp. different from Fusarium oxysporum and $F$. mangiferae is associated with mango malformation in Michoacán, Mexico. Plant Pathol. 57:781.

29. Schroers, H.-J., O’Donnell, K., Lamprecht, S. C., Kammeyer, P. L., Johnson, S., Sutton, D. A., Rinaldi, M. G., Geiser, D. M., and Summerbell, R. C. 2009. Taxonomy and phylogeny of the Fusarium dimerum species group. Mycologia 101:44-70.

30. Simpson, B. B., and Ogorzaly, M. C. 1995. Economic Botany: Plants in Our World. McGraw-Hill, Inc., New York.

31. Slippers, B., Stenlid, J., and Wingfield, M. J. 2005. Emerging pathogens: fungal host jumps following anthropogenic introduction. Trends Ecol. Evol. 20:420-421.

32. Steenkamp, E., Britz, H., Coutinho, T., Wingfield, B., Marasas, W., and Wingfield, M. 2000. Molecular characterization of Fusarium subglutinans associated with mango malformation. Mol. Plant Pathol. 1:187-193.

33. Steenkamp, E., Wingfield, B. D., Coutinho, T. A., Zeller, K. A., Wingfield, M. J., Marasas, W. F. O., and Leslie, J. F. 2000. PCR-based identification of MAT-1 and MAT-2 in the Gibberella fujikuroi species complex. Appl. Environ. Microbiol. 66:4378-4382.

34. Summanwar, A. S., Raychaudhuri, S. P., and Pathak, S. C. 1996. Association of the fungus Fusarium moniliforme Sheld. with the malformation of mango (Mangifera indica L.). Indian Phytopathol. 19:227-229.

35. Swofford, D. L. 2002. PAUP*. Phylogenetic Analysis Using Parsimony (*and other methods), version 4.0b10. Sinauer Associates, Sunderland, MA.

36. Taylor, J. W., Jacobson, D. J., Kroken, S., Kasuga, T., Geiser, D. M., Hibbett, D. S., and Fisher, M. C. 2000. Phylogenetic species recognition and species concepts in fungi. Fungal Genet. Biol. 31:21-32.

37. van Staden, J., and Nicholson, R. J. D. 1989. Cytokinins and mango flower malformation. The cytokinin complement produced by Fusarium moniliforme and the ability of the fungus to incorporate $\left(8-{ }^{14} \mathrm{C}\right)$ adenine into cytokinins. Physiol. Mol. Plant Pathol. 35:423-431.

38. Youssef, S. A., Maymon, M., Zveibil, A., Klein-Gueta, D., Sztejnberg, A., Shalaby, A. A., and Freeman, S. 2007. Epidemiological aspects of mango malformation disease caused by Fusarium mangiferae and source of infection in seedlings cultivated in orchards in Egypt. Plant Pathol. 56:257-263.

39. Zheng, Q., and Ploetz, R. 2002. Genetic diversity in the mango malformation pathogen and development of a PCR assay. Plant Pathol. 51:208-216.

40. Zwickl, D. J. 2006. Genetic algorithm approaches for the phylogenetic analysis of large biological sequence data sets under the maximum likelihood criterion. Ph.D. dissertation, The University of Texas, Austin. 